\title{
$P A X 4$ has the potential to function as a tumor suppressor in human melanoma
}

\author{
SHINYA HATA ${ }^{1,2}$, JUN-ICHI HAMADA ${ }^{1}$, KAZUHIKO MAEDA $^{1,2}$, TAICHI MURAI ${ }^{1}$, \\ MITSUHIRO TADA ${ }^{1}$, HIROSHI FURUKAWA ${ }^{2}$, ARATA TSUTSUMIDA ${ }^{2}$, \\ AKIRA SAITO $^{2}$, YUHEI YAMAMOTO ${ }^{2}$ and TETSUYA MORIUCHI ${ }^{1}$ \\ ${ }^{1}$ Division of Cancer-Related Genes, Institute for Genetic Medicine, Hokkaido University, \\ Kita-15, Nishi-7, Kita-ku, Sapporo 060-0815; ${ }^{2}$ Department of Plastic and Reconstructive \\ Surgery, Graduate School of Medicine, Hokkaido University, \\ Kita-15, Nishi-7, Kita-ku, Sapporo 060-8638, Japan
}

Received May 29, 2008; Accepted July 22, 2008

DOI: 10.3892/ijo_00000095

\begin{abstract}
We hypothesize that dysregulated expression levels of the developmental regulatory genes in the adult body result in tumor development and malignant progression. $P A X$ genes discovered as human orthologous genes of Drosophila 'paired' encode transcription factors, which control the expression of target genes to go on along the program of development. In this study, we first quantified expression of $9 P A X$ genes in human nevus pigmentosus tissues, melanoma tissues and melanoma cell lines by the real-time reverse transcription-PCR method. As a result, we found that the expression levels of PAX4 and PAX9 were extremely low in melanoma tissues and cell lines compared to nevus pigmentosus tissues. We then established melanoma cells overexpressing PAX4 and examined roles of PAX4 in cell growth. PAX4-overexpression reduced in vitro cell growth of human melanoma C8161 and MeWo cells. BrdUuptake assay and cell cycle analysis by flow cytometry indicated that the retardation of cell proliferation by PAX4overexpression was due to decreased DNA synthesis and cell cycle arrest at the G0/G1 phase. Furthermore, treatment of C8161 and MeWo cells with 5-azacytidine, a DNA demethylating agent, induced the expression of $P A X 4$, suggesting that DNA methylation repressed the $P A X 4$ gene expression in human melanoma. These results suggest that PAX4 functions as a potent tumor suppressor.
\end{abstract}

Correspondence to: Dr Jun-ichi Hamada, Division of CancerRelated Genes, Institute for Genetic Medicine, Hokkaido University, Kita-15, Nishi-7, Kita-ku, Sapporo 060-0815, Japan

E-mail: jhamada@igm.hokudai.ac.jp

Key words: PAX4, melanoma, tumor suppressor

\section{Introduction}

The development of cancer and its malignant progression can be considered as a phenomenon where cancer cells go on along a part of the program of embryogenesis. The genes regulating embryonic development spatio-temporally express themselves in an exquisitely controlled manner and execute programs such as cell growth, migration, differentiation and death. It is thought that abnormal cell behaviour of tumor cells result from the mis-execution of such a program.

$P A X$ genes, one of the developmental regulatory genes, were discovered as a human orthologous gene of Drosophila 'paired' (1). In human, $9 P A X$ genes have been identified $(2,3)$. All $P A X$ genes commonly possess a paired box, which consists of $381 \mathrm{bp}$. The paired box encodes paired domain through which PAX proteins bind to DNA in a sequencespecific manner in order to function as transcription factors.

It is known that abnormal expression of $P A X$ genes causes various types of congenital abnormality. For example, mutations of Paxl and Pax3 show the developmental defect of centrum and intervertebral disc and Splotch in mice, respectively $(4,5)$. The mutation of $P A X 2$ and $P A X 6$ causes optic nerve colobomas, renal anomalies and congenital eye abnormalities including aniridia, respectively $(6,7)$.

There are also some studies indicating that abnormal expression of $P A X$ genes is associated with cancer development and behaviour. Abnormal expression levels of $P A X$ genes through chromosomal translocations are found in rhabdomyosarcoma, thyroid cancer and acute lymphoblastic leukemia (8-11). Constitutive expression of $P A X 2, P A X 3$, $P A X 5$ or $P A X 6$ was detected in Ewing sarcoma, Wilms' tumor, medulloblastoma or thyroid cancer (12-15). Forced expression of Pax1,Pax2, Pax3, Pax6 or Pax8 transforms mouse fibroblasts (16). Some studies show that human $P A X 2$ or $P A X 3$ plays an essential role in survival of bladder and ovarian cancer cells or melanoma cells $(17,18)$. PAX proteins are also known to alter the expression of tumor suppressor genes: PAX2 and PAX3 regulate the expression of WT1 and PAX2, PAX5 and PAX8 repress the expression of p53 (19-21). Thus 
dysregulated expression of a particular $P A X$ gene(s) is likely to be involved in carcinogenesis and the malignant progression of a variety of cancers.

To explore malignant behaviour-associated $P A X$ genes, we established an analysis system to quantify the expression of 9 human $P A X$ genes at the level of mRNA. Using this system, we first compared the expression levels of $9 P A X$ genes between malignant melanoma specimens and nevus pigmentosus specimens. Furthermore, we addressed the tumor-suppressive role of $P A X 4$ of which expression was lost or extremely low in melanoma compared to nevus tissues.

\section{Materials and methods}

Clinical specimens. We studied 16 cutaneous melanoma tissues and 5 nevus tissues from patients who had undergone surgery at the Department of Plastic Surgery, Hokkaido University Medical Hospital between 1996 and 2003. The age of the patients ranged from 29 to 87 years and gender breakdown was 6 males and 10 females. The tumor status according to the TNM classification (UICC, 6th edition) was pT1aN0M0 in 3 cases, pT1bN0M0 in 1 case, pT1bN1bM0 in 1 case, pT2aN0M0 in 3 cases, pT3aN1aM0 in 1 case, pT4aN0M0 in 2 cases, pT4bN0M0 in 3 cases, pT4bN1M0 in 1 case and pT4bN2aM0 in 1 case. Complete written informed consent was obtained from all the patients.

Cells and culture condition. Human melanoma C8161 cells were kindly provided by Dr Motowo Nakajima (Johnson and Johnson, Tokyo, Japan). Origin and institution by which other cell lines (MeWo, G361, 9711, GAK, A375M and MMIV) were provided were described in our previous report (22). All the cell lines were grown on tissue culture dishes in a 1: $1(\mathrm{v} / \mathrm{v})$ mixture of Dulbecco's modified Eagle's minimum essential medium and Ham's F12 medium (DME/F12), supplemented with $10 \%$ heat-inactivated fetal bovine serum (FBS, Cambrex Bio Science, Wolkersville, MD). The cells were cultured at $37^{\circ} \mathrm{C}$ in a $\mathrm{CO}_{2}$ incubator $\left(5 \% \mathrm{CO}_{2}\right.$ and $95 \%$ air $)$.

Transfection and cell cloning. The human PAX4 expression vector, pCDNA3.1HisA-PAX4, was kindly donated by Dr Takahide Miyamoto (Shinshu University School of Medicine) (23). The transfection of pCDNA3.1HisA-PAX4 or pCDNA3.1HisA (Invitrogen, Carlsbad, CA) into MeWo and C8161 cells was performed with Lipofectamine (Invitrogen) and PLUS reagent (Invitrogen) according to the manufacturer's instructions. The cells stably transfected with the pCDNA3. 1HisA-PAX4 or pCDNA3.1HisA were selected by their resistance to $100 \mu \mathrm{g} / \mathrm{ml}$ of G418 sulfate (Cellgro, Herndon, VA). Cell cloning of the stable transfectants was performed by picking up the growing colony.

Immunoblot analysis. Melanoma cells cultured on 100-mm dishes were washed with cold PBS and then harvested with a cell scraper in lysis buffer $(10 \mathrm{mM}$ Tris- $\mathrm{HCl}, \mathrm{pH} 7.8 ; 1 \%$ NP40; $0.15 \mathrm{M} \mathrm{NaCl} ; 1 \mathrm{mM}$ EDTA; $10 \mu \mathrm{g} / \mathrm{ml}$ of leupeptin, aprotinin and pepstatin $\mathrm{A}$ ). The cell lysates were centrifuged at $20,000 \mathrm{x}$ g for $30 \mathrm{~min}$ at $4^{\circ} \mathrm{C}$. The supernatants were collected and the protein concentration was determined by modified Bradford assay (Bio-Rad protein assay, Bio-Rad,

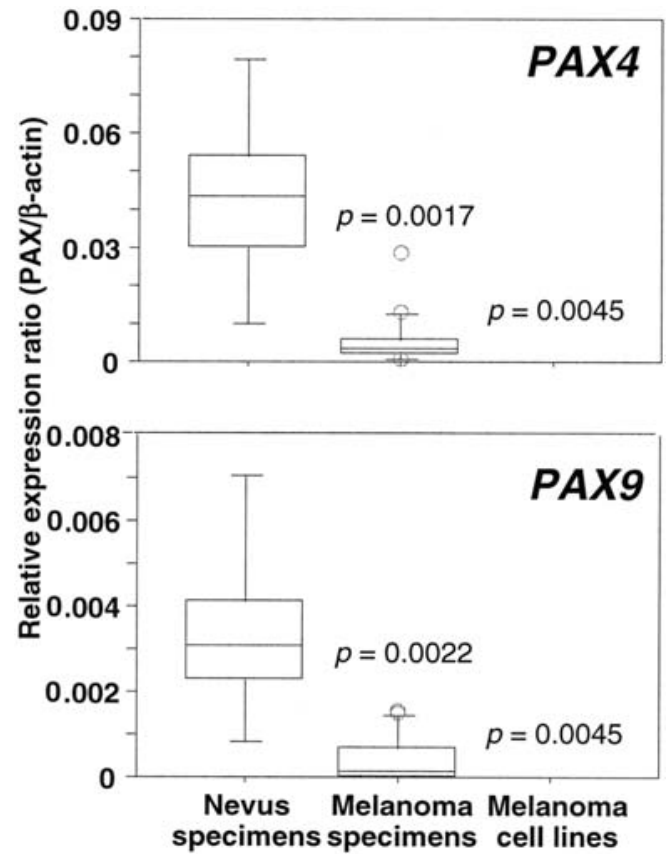

Figure 1. Decreased expression levels of $P A X 4$ and $P A X 9$ in melanoma tissues and cell lines. The expression levels of $P A X 4$ and $P A X 9$ were quantified by a real-time RT-PCR method. The distribution of the relative expression ratio $(P A X / \beta$-actin $)$ is shown by using boxplots. The central box in each plot shows the interquartile ( 25 th to 75 th percentile) range. The line in the box shows the median. The whiskers (vertical bars) were drawn to the 90th and 10 th percentile. Extreme values higher then the 90th percentile or $<10$ th percentile were marked with circles individually. P-values vs. nevus specimens were calculated by the Mann-Whitney U test.

Hercules, CA). Equal amounts of protein were separated by SDS-PAGE in $7.5 \%$ polyacrylamide gel and electrotransferred to nitrocellulose membranes. After blocking in TBS-T (20 mM Tris- $\mathrm{HCl}, \mathrm{pH} 7.5 ; 137 \mathrm{mM} \mathrm{NaCl} ; 0.1 \%$ Tween-20) containing $5 \%$ skim milk, the membranes were incubated with goat anti-human PAX4 antibody (Santa Cruz Biotech., Santa Cruz, $\mathrm{CA}$ ). The membranes were then incubated with peroxidesconjugated anti-goat IgG antibody (Santa Cruz Biotech.) and developed by reagents from the Enhanced Chemiluminescence Detection System (Amersham Pharmacia Biotech., Piscataway, NJ).

RNA extraction and $c D N A$ preparation. Total RNA was extracted from monolayer cultures of each cell line and clinical specimens by using Trizol (Invitrogen) according to the manufacturer's instructions. Total RNA $(1 \mu \mathrm{g})$ was subjected to cDNA synthesis in $100 \mu \mathrm{l}$ of reaction mixture containing Taq Man RT buffer (Applied Biosystems, Foster City, CA), $5.5 \mathrm{mM} \mathrm{MgCl}_{2}, 500 \mu \mathrm{M}$ dNTP, $2.5 \mu \mathrm{M}$ random hexamers, $0.4 \mathrm{U} / \mu 1$ RNAase inhibitor, $1.25 \mathrm{U} / \mu 1$ MultiScribe reverse transcriptase. The reverse transcription reaction was performed sequentially for $10 \mathrm{~min}$ at $25^{\circ} \mathrm{C}$, for $30 \mathrm{~min}$ at $48^{\circ} \mathrm{C}$ and for 5 min at $95^{\circ} \mathrm{C}$.

Quantitative real-time PCR. The PCR primers were designed with the use of Primer Express 1.5 (Applied Biosystems). The primer sequences for amplification of $9 P A X$ genes and $\beta$-actin are listed in Table I. Real-time PCR was carried out with a $15 \mathrm{~min}$ hot start at $95^{\circ} \mathrm{C}$ followed by a denaturation step 

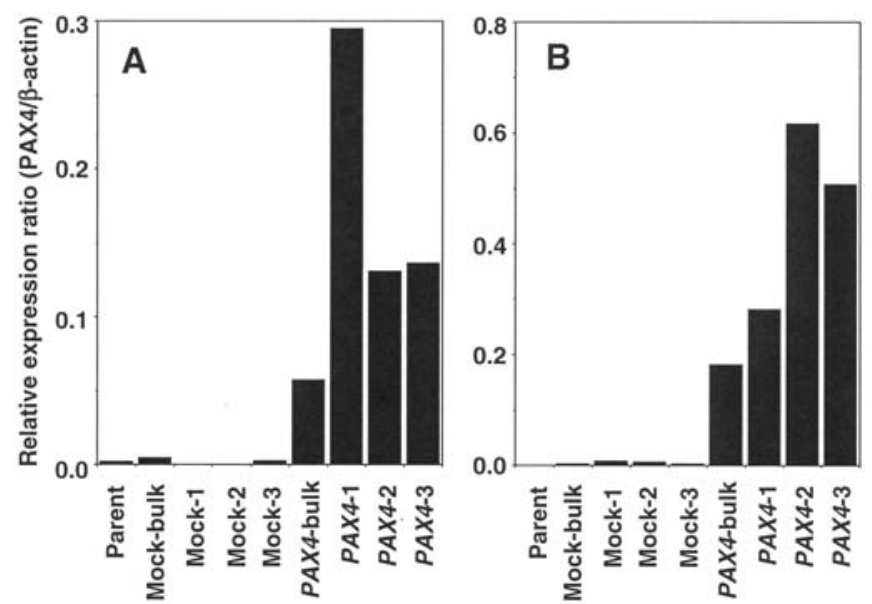

C

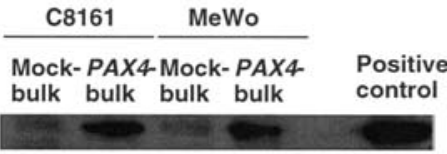

Figure 2. Expression levels of $P A X 4$ in the melanoma cells transfected with either $P A X 4$-expression vectors or the control vectors. Parent, Mock and $P A X 4$ indicate the cells before the transfection, the cells transfecetd with the control vectors and the cells transfected with the $P A X 4$ expression vectors, respectively. Mock-bulk and $P A X 4$-bulk indicate uncloned cells transfected with either vector. (A and B) Real-time RT-PCR analysis of PAX4 expression in the transfectants from C8161 (A) and MeWo (B). (C) Immunoblot analysis of cell lysates of the cell transfected with the PAX4 expression vectors or the control vectors.

at $94^{\circ} \mathrm{C}$ for $15 \mathrm{sec}$, an annealing step at $60^{\circ} \mathrm{C}$ for $30 \mathrm{sec}$ and an extention step at $72^{\circ} \mathrm{C}$ for 1 min for 40 cycles. Primer concentrations of reactions of each $P A X$ gene were $0.6 \mu \mathrm{M}$ except $0.3 \mu \mathrm{M}$ for $P A X 7$. Data were analysed with Sequence Detector Systems version 2.0 software (Applied Biosystems). The copy number of PCR products (cDNA) was quantified by using the standard curve method. Standard curves were drawn in the same method described in our previous study (24). Expression levels of $P A X$ genes were shown as the ratio of the target $P A X$ gene to the internal reference gene ( $\beta$-actin) expression based on the initial copy number calibrated along the standard curve.

Cell growth assay. The number of viable cells was estimated by colorimetric WST- 8 assay using the tetrazolium salt/formazan system (Dojindo, Kumamoto, Japan). Cell suspension $(100 \mu 1)\left(1 \times 10^{4} / \mathrm{ml}, \mathrm{DME} / \mathrm{F} 12-10 \% \mathrm{FBS}\right)$ was placed in each well of a 96 -well tissue culture plate. At intervals of $24 \mathrm{~h}$ after the cell seeding, $10 \mu \mathrm{l}$ of WST- 8 solution was added to the wells in a quadruplicate manner and incubated in a $\mathrm{CO}_{2}$ incubator. After $1 \mathrm{~h}$ of incubation, absorbance of soluble formazan was measured at $450 \mathrm{~nm}$ wavelength (655 nm reference wave length) by using a Microplate reader (Bio-Rad Laboratory, Hercules, CA). The data are presented as the mean \pm SD of quadruplicate wells.

Cell cycle analysis by flow cytometry. After cells were detached by the treatment with PBS (-) containing $0.2 \%$ trypsin and $2 \mathrm{mM}$ EDTA, they were washed twice with PBS (-). Cells $\left(1 \times 10^{6}\right)$ were fixed in $70 \% \mathrm{EtOH}$ at room temperature for $1 \mathrm{~h}$. After washing the cells with PBS, $100 \mu 1$ of
A

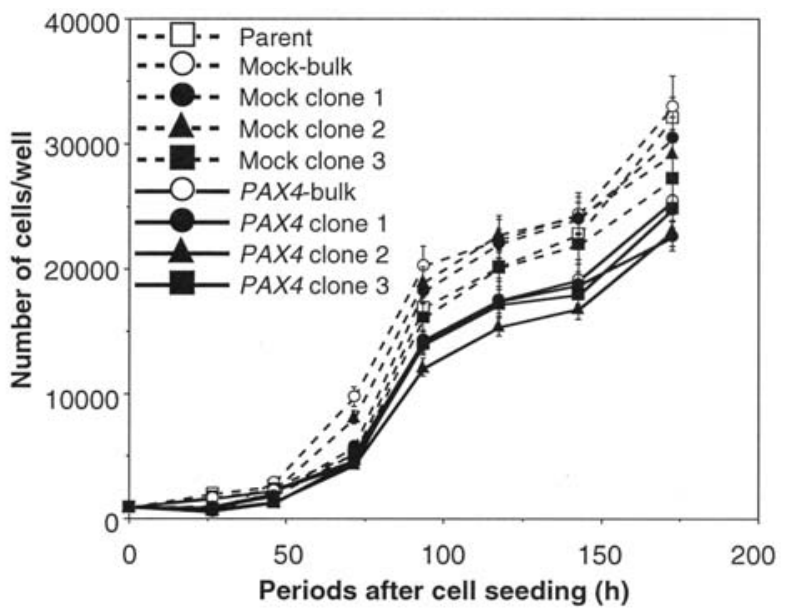

B

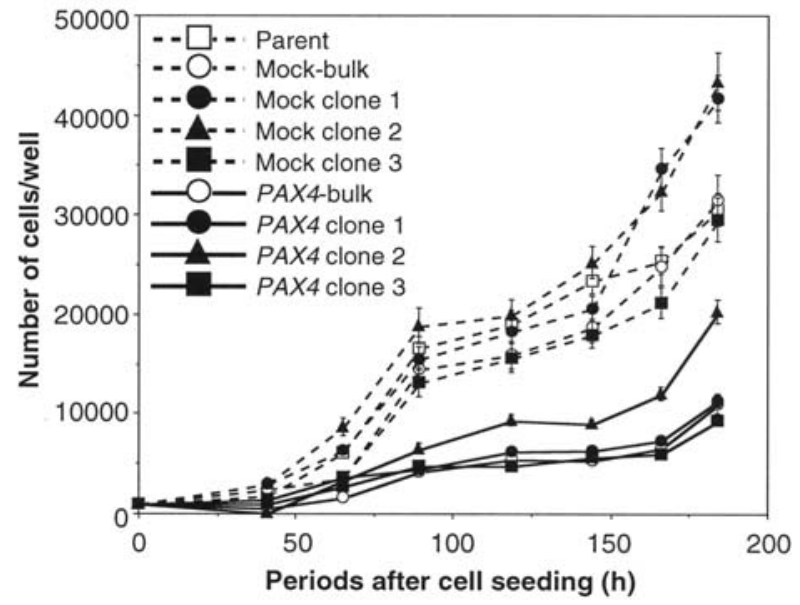

Figure 3. Cell growth of PAX4-overexpressing cell lines and the control cell lines. The cell number was converted from the data of the absorbance in colorimetric WST-8 assay. Data of the cell number are shown as mean \pm standard deviation. The p-value was $<0.01$ in the comparison between any of PAX4-overexpressing cell lines and any of the control cell lines (parent and Mock) $93.5 \mathrm{~h}$ (C8161) (A) and $89 \mathrm{~h}$ (MeWo) (B) after the cell seeding (by one-way ANOVA followed by Scheffe's $F$ analysis as a post-hoc test).

ribonuclease solution $(100 \mu \mathrm{g} / \mathrm{ml})$ was added to the cell pellet. After being kept at room temperature for $5 \mathrm{~min}$, the cells were stained with $400 \mu 1$ of propidium iodide (PI) solution $(50 \mu \mathrm{g} / \mathrm{ml})$ for evaluation of DNA content. Fluorescent intensity of PI was analysed by using FACS Calibur (Becton-Dickinson, San Jose, CA).

Assay for DNA synthesis. DNA synthesis was measured by means of 5-Bromo-2-deoxyuridine (BrdU) incorporation into cellular DNA with the use of colorimetric Cell Proliferation ELISA (BrdU) assay kit (Roche Diagnostics, Indianapolis, IN). Cells $\left(1 \times 10^{3} / 100 \mu 1 /\right.$ well, DME/F12-10\% FBS $)$ seeded on 96-well tissue culture plate were incubated in $\mathrm{CO}_{2}$ incubator for $24 \mathrm{~h}$. The medium was replaced with DME/F12-10\% FBS containing $10 \mu \mathrm{M}$ BrdU. After BrdU-pulsing for $2 \mathrm{~h}$, the cells were fixed and incubated with peroxidase-labelled anti-BrdU antibody. Then, tetramethyl-benzidine, a peroxidase substrate, was added to each well and the reaction was then stopped with $0.2 \mathrm{M} \mathrm{H}_{2} \mathrm{SO}_{4}$. Absorbance was measured at $450 \mathrm{~nm}$ wavelength (655 $\mathrm{nm}$ reference wave length) by using a Microplate reader. The data are presented as the mean $\pm \mathrm{SD}$ of quadruplicate wells. 
Table I. Primer pairs for real-time PCR.

\begin{tabular}{|c|c|c|}
\hline Genes & Accession No. & Primer sequences ( $5^{\prime}$ to $3^{\prime}$ ) \\
\hline$P A X 1$ & AL035562 & $\begin{array}{l}\text { Forward: CACCCCCGCAGTGAATG } \\
\text { Reverse: CGCCCACGGCAGAGA }\end{array}$ \\
\hline$P A X 2$ & AH006910 & $\begin{array}{l}\text { Forward: TGGTCTGGACTTTAAGAGATGTGTGTCT } \\
\text { Reverse: GAAGGTGTCAGCTCGCAAGTG }\end{array}$ \\
\hline$P A X 3$ & AH003224 & $\begin{array}{l}\text { Forward: CCTCTTACCAGCCCACATCTATTC } \\
\text { Reverse: CGTGCTTTGGTGTACAGTGCTT }\end{array}$ \\
\hline PAX4 & AB008913 & $\begin{array}{l}\text { Forward: GGCACTGGAGAAAGAGTTCC } \\
\text { Reverse: CTTGAGCTTCTCTTGCCGAC }\end{array}$ \\
\hline$P A X 5$ & M96944 & $\begin{array}{l}\text { Forward: TGTCAGGCCCTGCGACAT } \\
\text { Reverse: GGCGACCTTTGGTTTGGAT }\end{array}$ \\
\hline PAX6 & M77844 & $\begin{array}{l}\text { Forward: GGAAGCTGCAAAGAAATAGAACATC } \\
\text { Reverse: TTCTCGGGCAAACACATCTG }\end{array}$ \\
\hline$P A X 7$ & X96743 & $\begin{array}{l}\text { Forward: GCCACAGCTTCTCCAGCTACTC } \\
\text { Reverse: ATGCTCATCACCTGAGGAGACA }\end{array}$ \\
\hline$P A X 8$ & L19606 & $\begin{array}{l}\text { Forward: TGAGGGCGTCTGTGACAATG } \\
\text { Reverse: AGCTGTCCATAGGGAGGTTGAA }\end{array}$ \\
\hline$P A X 9$ & ВС001159 & $\begin{array}{l}\text { Forward: GAATGCAGGCAGCCAGAGA } \\
\text { Reverse: GGAGACGGAATTTCCCATCA }\end{array}$ \\
\hline$\beta$-actin & XM037235 & $\begin{array}{l}\text { Forward: TTGCCGACAGGATGCAGAA } \\
\text { Reverse: GCCGATCCACACGGAGTACT }\end{array}$ \\
\hline
\end{tabular}
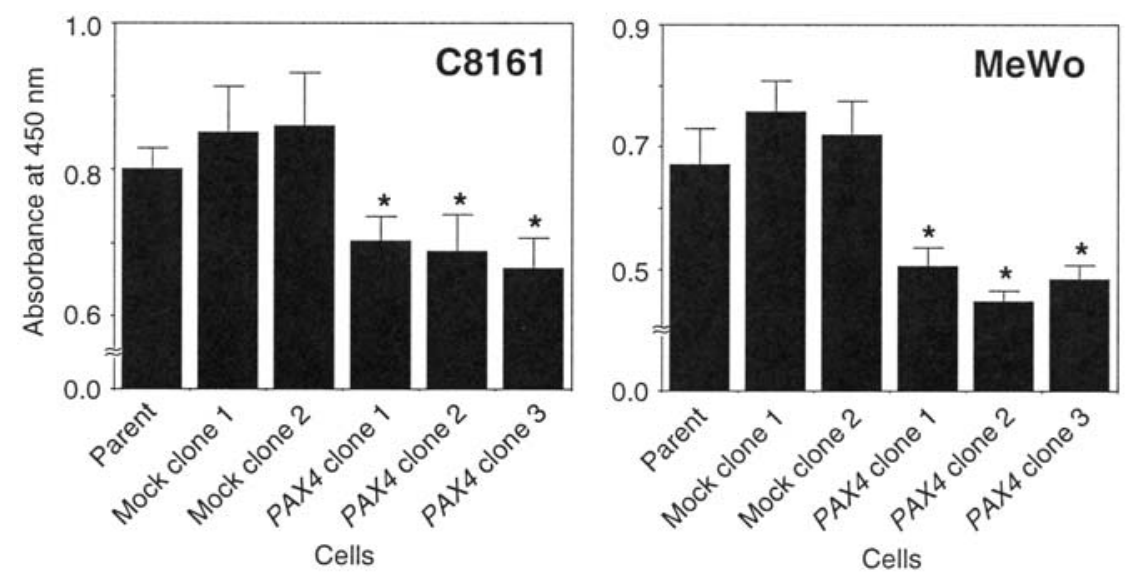

Figure 4. DNA synthesis of PAX4-overexpressing cell lines and control cell lines. DNA synthesis was evaluated by BrdU incorporation assay. There was a statistically significant difference between each of the PAX4-overexpressing cell lines (PAX4 clone 1,2 and 3) and each of the control cell lines (parent, Mock clone 1 and 2 ) by one-way ANOVA followed by Scheffe's $F$ analysis as a post-hoc test (p<0.01).

Treatment of melanoma cells with 5-azacytidine, a DNA demethylating agent or trichostatin A, a histone deacetylase inhibitor. Cells were plated in 100-mm tissue culture dishes at a cell density of $1 \times 10^{6} / \mathrm{dish}$. After $24 \mathrm{~h}$, the cells were treated with $5 \mu \mathrm{M}$ 5-azacytidine (Sigma, St. Louis, MO) for 2 days, or with 1 to $100 \mathrm{nM}$ trichostatin A (Sigma) for 2 to 5 days.

\section{Results}

Expression levels of 9 PAX genes in human melanoma specimens, melanoma cell lines and nevus specimens. We first analysed the expression levels of 9 types of $P A X$ genes in
16 melanoma specimens, 7 melanoma cell lines and 5 nevus specimens by a real-time RT-PCR method. Of the $9 P A X$ genes, $3 P A X$ genes such as $P A X 3, P A X 4$ and $P A X 9$ were expressed in nevus tissues. As shown in Fig. 1, the expression levels of $P A X 4$ and $P A X 9$ in the melanoma specimens and melanoma cell lines were significantly low compared to those in the nevus specimens $(\mathrm{p}<0.01$, Mann-Whitney $\mathrm{U}$ test). None of the melanoma cell lines showed expression of the two $P A X$ genes.

Overexpression of PAX4 in human melanoma C8161 and MeWo cells transfected with the PAX4 expression vector. As 

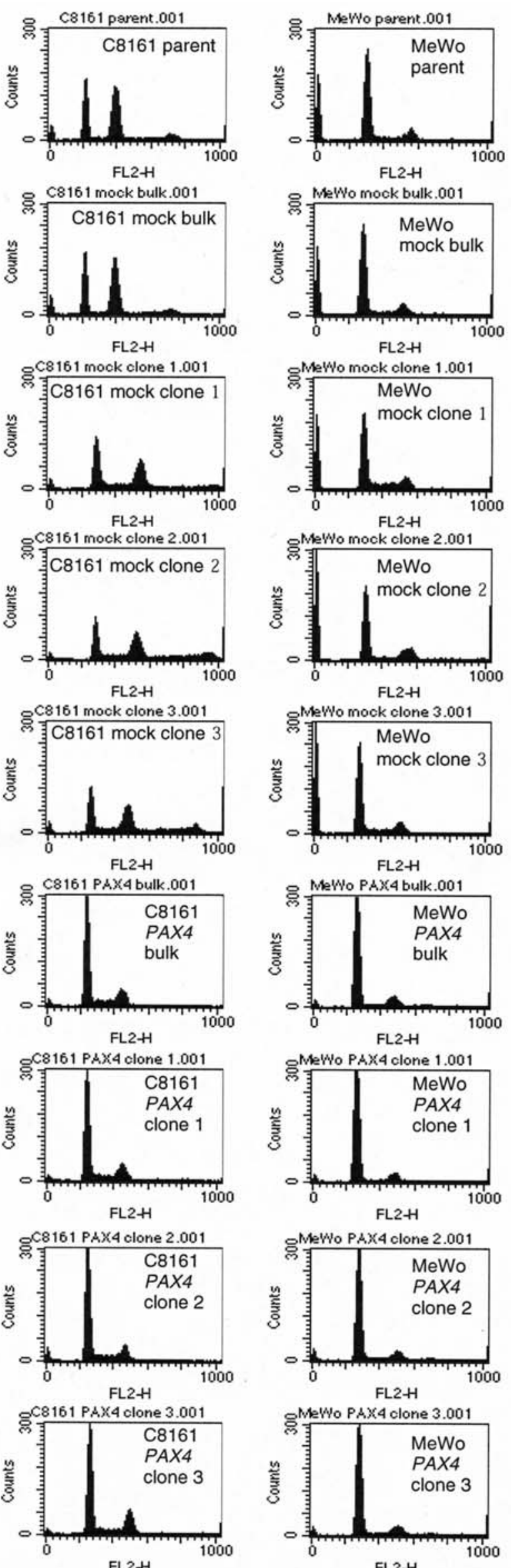

Figure 5. Cell cycle analysis of PAX4-overexpressing cell lines and control cell lines. Cell cycle analysis was performed by detecting fluorescence intensity of the cells stained with propidium iodide with flow cytometry. Left panel,data of C8161 cells; right panel, MeWo cells.

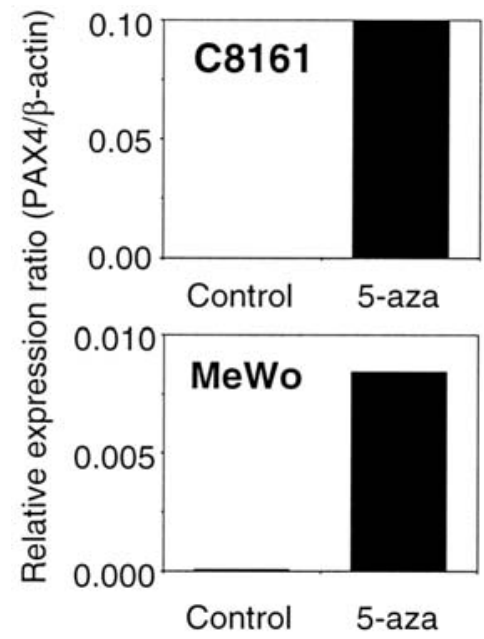

Figure 6. Induction of $P A X 4$ expression by treatment with 5-azacytidine (5-aza), a demethylating agent. RNA was extracted from the cells treated with $5 \mu \mathrm{M} 5$-aza for 2 days and $P A X 4$ expression was analysed by real-time RT-PCR method.

the expression of PAX4 was lost or low in melanoma tissues and melanoma cell lines compared to nevus tissues, we speculated that $P A X 4$ functioned as a tumor suppressor. To examine whether the expression of $P A X 4$ influences the proliferative behaviour of melanoma cells, we stably transfected $\mathrm{C} 8161$ and MeWo cells with a PAX4 expression vector, pCDNA3. 1HisA-PAX4. The cell lines were transfected with empty pCDNA3.1HisA (mock transfectants) as a control. RNA was extracted from each parent line and transfected sublines and subjected to the analysis of expression of PAX4 by a real-time RT-PCR method. In the C8161 and MeWo cell lines, all the cloned cell lines transfected with $P A X 4$ and $P A X 4$-transfected cell lines before cell cloning showed higher expression of $P A X 4$ than the parent and mock-transfected cells (Fig. 2A and B). Immunoblot analysis also revealed that $P A X 4$-transfected cells expressed the PAX4 protein (Fig. 2C).

Decreased cell growth of PAX4-overexpressing melanoma cells. We examined the influence of PAX4-overexpression on cell growth of melanoma cells by WST-8 assay. As shown in Fig. 3A, the growth of all the C8161 cell lines overexpressing $P A X 4$ was significantly lower than the control cell lines (parent and Mock-transfectants) after incubation for $93.5 \mathrm{~h}$ $(\mathrm{p}<0.01)$. In MeWo cells, the growth of all the cell lines overexpressing $P A X 4$ was significantly lower than any of the control cell lines after incubation for $89 \mathrm{~h}(\mathrm{p}<0.01)$. The inhibitory effect of $P A X 4$-overexpression on the cell growth was more prominent in MeWo cells compared to C8161 cells.

Decrease in DNA synthesis in melanoma cells by PAX4overexpression. To examine whether the growth inhibition by PAX4-overexpression was due to a decrease in DNA synthesis, we performed a BrdU-uptake assay. As shown in Fig. 4A and $\mathrm{B}$, the activity of DNA synthesis diminished by PAX4overexpression in C8161 and MeWo cells.

Increase in G0/G1 phase fraction of cell cycle in melanoma cells by PAX4-overexpression. We then analysed cell cycle 
distribution by flow cytometry in order to clarify whether decreased DNA synthesis by $P A X 4$-overexpression was related to cell cycle arrest. In C8161 and MeWo cells, PAX4overexpression extended the $\mathrm{G} 0 / \mathrm{G} 1$ phase fraction and reduced $\mathrm{S}$ or $\mathrm{G} 2 / \mathrm{M}$ phase fraction (Fig. 5), while no essential changes were detected in the Mock transfectants as compared to the parent cells.

Induction of PAX4 expression by treatment with 5-azacytidine. We tested whether the silencing of the PAX4 gene in C8161 and MeWo cells was due to the DNA methylation or histone deacetylation. When the two cell lines were treated with $5 \mu \mathrm{M}$ of the demethylating agent 5-azacytidine for 2 days, they expressed the PAX4 gene (Fig. 6). However, treatment with histone deacethylase inhibitor trichostatin A did not induce the expression of the PAX4 gene in any of the cell lines (data not shown).

\section{Discussion}

Nine members have been identified in the human PAX gene family. They are classified into 4 groups based on the structural domains other than the paired domain (25). The first group (group III: $P A X 3$ and $P A X 7$ ) contains an octapeptide motif and a homeodomain; second one (group II: $P A X 2, P A X 5$ and $P A X 8$ ) contains an octapeptide motif and a truncated homeodomain; third one (group IV: $P A X 4$ and $P A X 6$ ) or fourth one (group I: $P A X 1$ and $P A X 9$ ) contains only a homeodomain or an octapeptide motif. So far, there are many studies indicating that $P A X$ genes of group II and III contribute to oncogenesis. These $P A X$ genes are often highly expressed in a variety of tumors: $P A X 2$ in prostate cancer (26), $P A X 5$ in medulloblastoma (14), $P A X 8$ in ovarian cancer (17) and $P A X 3$ and $P A X 7$ in Ewing sarcoma $(12,27)$. Furthermore, experimental analyses also showed oncogenic functions of these $P A X$ genes: Silencing of $P A X 2$ by antisense oligonucleotides or siRNA suppressed the growth of renal cancer cells (28) or induced apoptosis in ovarian and bladder cancer cells (17); mouse Pax 1, 2, 3, 6 and 8 in vitro transformed NIH $3 \mathrm{~T} 3$ cells and the transformants formed tumors in mice (16); $P A X 2,5$ and 8 inhibited transactivation of a p53-responsive reporter in culture cells (21).

However, there are few studies on anti-oncogenic functions of $P A X$ genes; for example, $P A X 2$ and $P A X 8$ are able to transactivate WT1, one of the tumor suppressor genes and thus they may be considered to work tumor-suppressively $(19,29)$. A low level of PAX6 expression in malignant astrocytic gliomas correlates with unfavourable outcomes (30) and overexpression of PAX6 suppresses cell growth due to G1 arrest of cell cycle in human glioma cells (31).

Here, we showed for the first time that PAX4 potentially functioned as a tumor suppressor in human melanoma cells. Namely, the expression levels of PAX4 were significantly low in melanoma tissues compared to nevus tissues. Furthermore, forced expression of $P A X 4$ suppressed the growth of melanoma cells, mainly due to a decrease in DNA synthesis through cell cycle arrest at the G1 phase. This phenomenon is similar to the growth inhibition of glioma cells by $P A X 6$, as mentioned above (31). It is notable that $P A X 4$ has common features with $P A X 6$. Both belong to the same group (group IV) of the $P A X$ family and are required for the normal development of pancreas, especially hormone-producing endocrine cells (32). Additionally, they are capable of binding a common element in the glucagons, insulin and somatostatin promoters $(33,34)$. It is unlikely that regulatory functions of the transcription of these genes related to the pancreas development work as tumor suppressors. However, it may be reasonable to think that $P A X 4$ as well as $P A X 6$ affects the expression levels of or interactions with molecules associated with the control system of the cell cycle, not as yet characterized. Further studies should help to identify the molecules targeted by PAX4 .

How is the expression of $P A X 4$ suppressed in melanoma? The expression levels of PAX4 in C8161 and MeWo were induced by treatment with 5-azacytidine, a DNA-demethylating agent but not TSA, a histone deacethylase inhibitor. No deletion of the PAX4 gene in these cell lines was detected by genomic DNA analysis (unpublished data). Futhermore, the deletion of chromosome $7 \mathrm{q}$ on which the PAX4 gene was localized was not detected although its amplification was reported $(35,36)$. Thus, the suppression of $P A X 4$ in melanoma is likely to be due to DNA-methylation although we need to identify the methylated sites.

This is the first study suggesting that $P A X 4$ potentially functions as a tumor suppressor. Although it is necessary that further studies reveal detailed molecular mechanisms by which $P A X 4$ works as a tumor suppressor, $P A X 4$ may provide an important avenue for a therapeutic strategy to melanoma.

\section{Acknowledgements}

We thank Dr Takahide Miyamoto for the generous gift of the human PAX4 expression vector and Ms. Masako Yanome for her help in the preparation of the manuscript. This study was supported in part by a Grant-in-Aid for Scientific Research (B) to Y.Y. from the Ministry of Education, Culture, Sports, Science and Technology of Japan.

\section{References}

1. Noll M: Evolution and role of Pax genes. Curr Opin Genet Dev 3: 595-605, 1993.

2. Dahl E, Koseki H and Balling R: Pax genes and organogenesis. Bioessays 19: 755-765, 1997.

3. Chi $\mathrm{N}$ and Epstein JA: Getting your Pax straight: pax proteins in development and disease. Trends Genet 18: 41-47, 2002.

4. Wallin J, Wilting J, Koseki H, Fritsch R, Christ B and Balling R: The role of Pax-1 in axial skeleton development. Development 120: 1109-1121, 1994.

5. Epstein DJ, Vogan KJ, Trasler DG and Gros P: A mutation within intron 3 of the Pax-3 gene produces aberrantly spliced mRNAtranscripts in the splotch (Sp) mouse mutant. Proc Natl Acad Sci USA 90: 532-536, 1993.

6. Sanyanusin P, Schimmenti LA, McNoe LA, et al: Mutation of the PAX2 gene in a family with optic nerve colobomas, renal anomalies and vesicoureteral reflux. Nat Genet 9: 358-364, 1995.

7. Glaser T, Jepeal L, Edwards JG, Young SR, Favor J and Maas RL: PAX6 gene dosage effect in a family with congenital cataracts, aniridia, anophthalmia and central nervous system defects. Nat Genet 7: 463-471, 1994.

8. Galili N, Davis RJ, Fredericks WJ, et al: Fusion of a fork head domain gene to PAX3 in the solid tumour alveolar rhabdomyosarcoma. Nat Genet 5: 230-235, 1993.

9. Shapiro DN, Sublett JE, Li B, Downing JR and Naeve CW: Fusion of PAX3 to a member of the forkhead family of transcription factors in human alveolar rhabdomyosarcoma. Cancer Res 53: 5108-5112, 1993. 
10. Kroll TG, Sarraf P, Pecciarini L, Chen CJ, Mueller E, Spiegelman BM and Fletcher JA: PAX8-PPARgammal fusion oncogene in human thyroid carcinoma. Science 289: 1357-1360, 2000 .

11. Cazzaniga G, Daniotti M, Tosi S, et al: The paired box domain gene PAX5 is fused to ETV6/TEL in an acute lymphoblastic leukemia case. Cancer Res 61: 4666-4670, 2001.

12. Schulte TW, Toretsky JA, Ress E, Helman L and Neckers LM: Expression of PAX3 in Ewing's sarcoma family of tumors. Biochem Mol Med 60: 121-126, 1997.

13. Tagge EP, Hanson P, Re GG, Othersen HB Jr, Smith CD and Garvin AJ: Paired box gene expression in Wilms' tumor. J Pediatr Surg 29: 134-141, 1994.

14. Kozmik Z, Sure U, Rüedi D, Busslinger M and Aguzzi A: Deregulated expression of PAX5 in medulloblastoma. Proc Natl Acad Sci USA 92: 5709-5713, 1995.

15. Fabbro D, Di Loreto C, Beltrami CA, Belfiore A, Di Lauro R and Damante G: Expression of thyroid-specific transcription factors TTF-1 and PAX-8 in human thyroid neoplasms. Cancer Res 54: 4744-4749, 1994.

16. Maulbecker CC and Gruss P: The oncogenic potential of Pax genes. EMBO J 12: 2361-2367, 1993.

17. Muratovska A, Zhou C, He S, Goodyer P and Eccles MR: Paired-Box genes are frequently expressed in cancer and often required for cancer cell survival. Oncogene 22: 7989-7997, 2003.

18. Scholl FA, Kamarashev J, Murmann OV, Geertsen R, Dummer R and Schäfer BW: PAX3 is expressed in human melanomas and contributes to tumor cell survival. Cancer Res 61: 823-826, 2001.

19. Dehbi M, Ghahremani M, Lechner M, Dressler G and Pelletier J: The paired-box transcription factor, PAX2, positively modulates expression of the Wilms' tumor suppressor gene (WT1). Oncogene 13: 447-453, 1996.

20. Fraizer GC, Shimamura R, Zhang X and Saunders GF: PAX 8 regulates human WT1 transcription through a novel DNA binding site. J Biol Chem 272: 30678-30687, 1997.

21. Stuart ET, Haffner R, Oren M and Gruss P: Loss of $\mathrm{p} 53$ function through PAX-mediated transcriptional repression. EMBO J 14: 5638-5645, 1995.

22. Okubo Y, Hamada J, Takahashi Y, et al: Transduction of HOXD3-antisense into human melanoma cells results in decreased invasive and motile activities. Clin Exp Metastasis 19: 503-511, 2002.

23. Miyamoto T, Kakizawa T, Ichikawa K, Nishio S, Kajikawa S and Hashizume K: Expression of dominant negative form of PAX4 in human insulinoma. Biochem Biophys Res Commun 282: 34-40, 2001.
24. Takahashi Y, Hamada J, Murakawa K, et al: Expression profiles of 39 HOX genes in normal human adult organs and anaplastic thyroid cancer cell lines by quantitative real-time RT-PCR system. Exp Cell Res 293: 144-153, 2004.

25. Robson EJ, He SJ and Eccles MR: A PANorama of PAX genes in cancer and development. Nat Rev Cancer 6: 52-62, 2006.

26. Khoubehi B, Kessling AM, Adshead JM, Smith GL, Smith RD and Ogden CW: Expression of the developmental and oncogenic PAX2 gene in human prostate cancer. J Urol 165: 2115-2120, 2001.

27. Barr FG, Fitzgerald JC, Ginsberg JP, Vanella ML, Davis RJ and Bennicelli JL: Predominant expression of alternative PAX3 and PAX7 forms in myogenic and neural tumor cell lines. Cancer Res 59: $5443-5448,1999$.

28. Gnarra JR and Dressler GR: Expression of Pax-2 in human renal cell carcinoma and growth inhibition by antisense oligonucleotides. Cancer Res 55: 4092-4098, 1995.

29. Dehbi M and Pelletier J: PAX8-mediated activation of the wt1 tumor suppressor gene. EMBO J 15: 4297-4306, 1996.

30. Zhou YH, Tan F, Hess KR and Yung WK: The expression of PAX6, PTEN, vascular endothelial growth factor, and epidermal growth factor receptor in gliomas: relationship to tumor grade and survival. Clin Cancer Res 9: 3369-3375, 2003

31. Zhou YH, Wu X, Tan F, et al: PAX6 suppresses growth of human glioblastoma cells. J Neurooncol 71: 223-229, 2005.

32. Dohrmann C, Gruss P and Lemaire L: Pax genes and the differentiation of hormone-producing endocrine cells in the pancreas. Mech Dev 92: 47-54, 2000.

33. Sosa-Pineda B, Chowdhury K, Torres M, Oliver G and Gruss P The Pax 4 gene is essential for differentiation of insulin-producing $B$ cells in the mammalian pancreas. Nature 386: 399-402, 1997.

34. St-Onge L, Sosa-Pineda B, Chowdhury K, Mansouri A and Gruss P: Pax6 is required for differentiation of glucagonsproducing $\alpha$-cells in mouse pancreas. Nature 387: 406-409, 1997.

35. Morita R, Fujimoto A, Hatta N, Takehara K and Takata M: Comparison of genetic profiles between primary melanomas and their metastases reveals genetic alterations and clonal evolution during progression. J Invest Dermatol 111: 919-924, 1998.

36. Gordon KB, Thompson CT, Char DH, O'Brien JM, Kroll S, Ghazvini S and Gray JW: Comparative genomic hybridization in the detection of DNA copy number abnormalities in uveal melanoma. Cancer Res 54: 4764-4768, 1994. 